\title{
BMJ Open Comparison of the efficacy and safety of drug therapies for macular edema secondary to central retinal vein occlusion
}

\author{
Tianwei Qian, ${ }^{1}$ Mengya Zhao, ${ }^{1}$ Yongjing Wan, ${ }^{2}$ MengXiao Li, ${ }^{2}$ Xun $\mathrm{Xu}^{1}$
}

To cite: Qian T, Zhao M, Wan $\mathrm{Y}$, et al. Comparison of the efficacy and safety of drug therapies for macular edema secondary to central retinal vein occlusion. BMJ Open 2018;8:e22700. doi:10.1136 bmjopen-2018-022700

- Prepublication history and additional material for this paper are available online. To view these files, please visit the journal online (http://dx.doi. org/10.1136/bmjopen-2018022700).

Received 9 March 2018

Revised 21 June 2018

Accepted 27 September 2018

Check for updates

(c) Author(s) (or their employer(s)) 2018. Re-use permitted under CC BY-NC. No commercial re-use. See rights and permissions. Published by BMJ.

${ }^{1}$ Department of Ophthalmology, Shanghai General Hospital, Shanghai Jiaotong University School of Medicine; Shanghai Key Laboratory of Ocular Fundus Diseases, Shanghai, China

${ }^{2}$ School of Information Science and Engineering, East China University of Science and Technology, Shanghai, China

Correspondence to

Professor Xun Xu;

drxuxun@sjtu.edu.cn

\section{ABSTRACT}

Objectives To evaluate the efficacy and safety of antivascular endothelial growth factor (VEGF) agents and corticosteroids for the treatment of macular oedema (ME) secondary to central retinal vein occlusion (CRVO). Design Systematic review and network meta-analysis. Participants Patients from previously reported randomised controlled trials (RCTs) comparing anti-VEGF and corticosteroids for the treatment of ME secondary to CRVO.

Methods Literature searches were conducted using PubMed, Medline, Embase, Cochrane Library and clinicaltrials.gov until March 2017. Therapeutic effects were estimated using the proportions of patients gaining/ losing $\geq 15$ letters, best-corrected visual acuity (BCVA) and central retinal thickness (CRT). Treatment safety was estimated using the proportions of adverse events, namely increased intraocular pressure (IOP), cataracts, vitreous haemorrhage $(\mathrm{VH})$ and retinal tear. The software ADDIS (V.1.16.8) was used for analysis. Treatment effect and safety of different drugs could be ranked based on simulation.

Results Eleven RCTs comprising 2060 patients were identified. Regarding patients gaining $\geq 15$ letters, aflibercept and ranibizumab were significantly more effective than sham/placebo at 6 months. Regarding patients losing $\geq 15$ letters at 6 months, ranibizumab showed significant improvement compared with dexamethasone. Aflibercept, bevacizumab or ranibizumab showed greater improvements in BCVA than sham/ placebo at 6 months. Intravitreal ranibizumab injection demonstrated greater CRT reduction than both sham and dexamethasone did. Dexamethasone had a higher risk of increased IOP than aflibercept and ranibizumab. Ranibizumab demonstrated a greater risk of cataracts than dexamethasone. Aflibercept and ranibizumab demonstrated low incidence of VH and retinal tear, respectively. Aflibercept had a slight advantage over ranibizumab as assessed by benefit-risk analysis.

Conclusions Anti-VEGF agents have advantages in the treatment of ME secondary to CRVO. Aflibercept and ranibizumab showed marked BCVA improvement and CRT reduction. Aflibercept may have a slight advantage over ranibizumab. The results of this study can serve as a reference for clinicians to provide patient-tailored treatment.

PROSPER0 registration number CRD42017064076.
Strengths and limitations of this study

This meta-analysis included the most recent reports.

- Strict inclusion and exclusion criteria were used to perform a comprehensive comparison of aflibercept, ranibizumab, bevacizumab, pegaptanib, dexamethasone and triamcinolone treatments.

- Our data contained some biases that might have influenced our results. In the 11 literature included, three of them did not illustrate blinding of participants and two of them reported incomplete outcome data.

- Detailed data at long-term follow-up time points are required to improve the accuracy and robustness of our findings.

- The details of adverse events were not always reported in each study.

\section{INTRODUCTION}

Central retinal vein occlusion $(\mathrm{CRVO})$, a common retinal vascular disorder, is characterised by dilated and tortuous retinal veins with haemorrhages in all four quadrants of the retina. ${ }^{2}$ CRVO can reduce vision severely, ${ }^{34}$ and its prevalence is estimated at 0.80 per 1000 persons, indicating that approximately 2.5 million adults are affected by CRVO globally. ${ }^{1}$ CRVO is caused by a combination of risk factors, including advanced age, atherosclerosis, hypertension, diabetes mellitus, thrombophilia, hyperlipidaemia, glaucoma and other vessel wall changes or haemodynamic abnormalities. ${ }^{5}{ }^{6}$ Macular oedema (ME) is the most common complication in CRVO that can lead to impaired central vision, ${ }^{7}$ and ME secondary to CRVO is the second most common retinal vascular disease after diabetic retinopathy. ${ }^{189}$

The serious consequences of CRVO and its increasing prevalence make effective and widely applicable treatments necessary. Preventing ME and improving visual acuity (VA) are the two most important goals of 
treatment of ME secondary to CRVO. During the past several decades, various therapeutic approaches have been advocated for CRVO. The Central Vein Occlusion Study demonstrated that macular grid photocoagulation could decrease ME in patients with CRVO; however, it failed to improve VA when compared with that in the observation group. ${ }^{10}$ Although intravitreal corticosteroid agents (eg, triamcinolone acetonide injections and dexamethasone implants), which have anti-inflammatory, antiangiogenic and antioedematous properties, ${ }^{12}$ demonstrate some adverse events (AEs), they have been used to treat ME and improve VA in CRVO patients. Intravitreal triamcinolone has recently been shown to have a beneficial effect on ME secondary to CRVO and a preventive effect on neovascularisation. ${ }^{13-15}$ Kuppermann et al also reported that dexamethasone implants might be a potential treatment option for persistent ME. ${ }^{16}$

Vascular endothelial growth factor (VEGF) is a homodimeric protein that can stimulate vascular endothelial cell growth and induce vascular permeability. ${ }^{17}$ It plays a crucial role in the pathophysiology process of $\mathrm{ME},{ }^{18}$ and its levels were elevated in the ocular fluids of patients with CRVO. ${ }^{19}$ Therefore, several anti-VEGF agents, including aflibercept, ranibizumab, bevacizumab and pegaptanib, have been widely used for treating ME secondary to CRVO, because they significantly improve visual and anatomic outcomes in CRVO patients. ${ }^{20-23}$

Currently, intravitreal corticosteroid agents and intravitreal anti-VEGF agents are the common clinical therapies for ME secondary to CRVO. Nevertheless, these different drug treatment strategies have not been comprehensively compared, and there are no head-tohead trials or clear guidance to determine the best treatment strategy for CRVO patients. Therefore, a systematic review of randomised controlled trials (RCTs) is needed to indirectly compare the efficacies of anti-VEGF agents and intravitreal corticosteroids agents for treating $\mathrm{ME}$ secondary to CRVO.

A previous network meta-analysis of RCTs that examined CRVO treatments had mainly focused on the efficacy outcomes at 6 months and failed to include pegaptanib. ${ }^{24}$ In addition, it only considered the functional outcomes

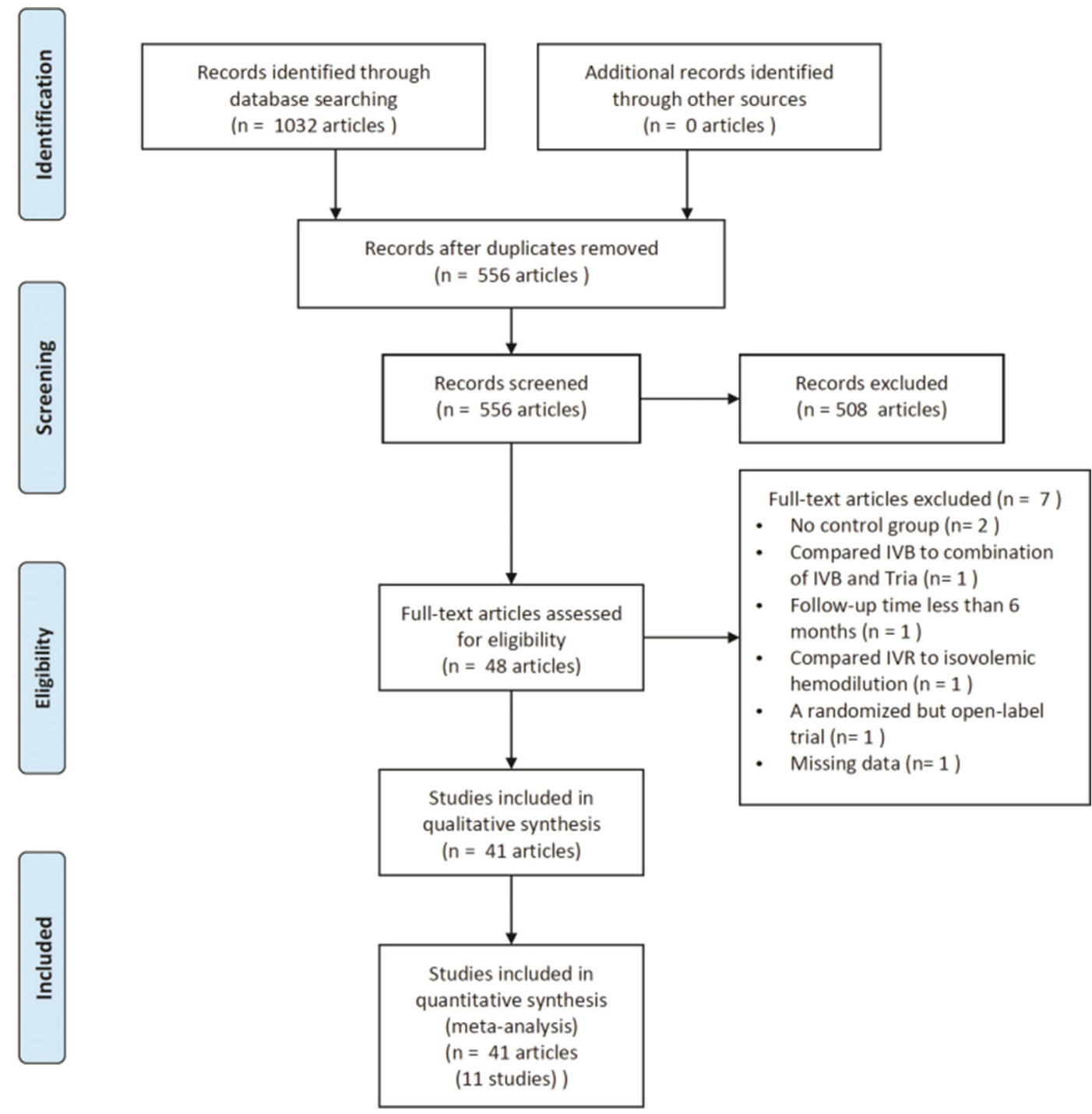

Figure 1 Study selection flow diagram. IVB, intravitreal bevacizumab injections. 


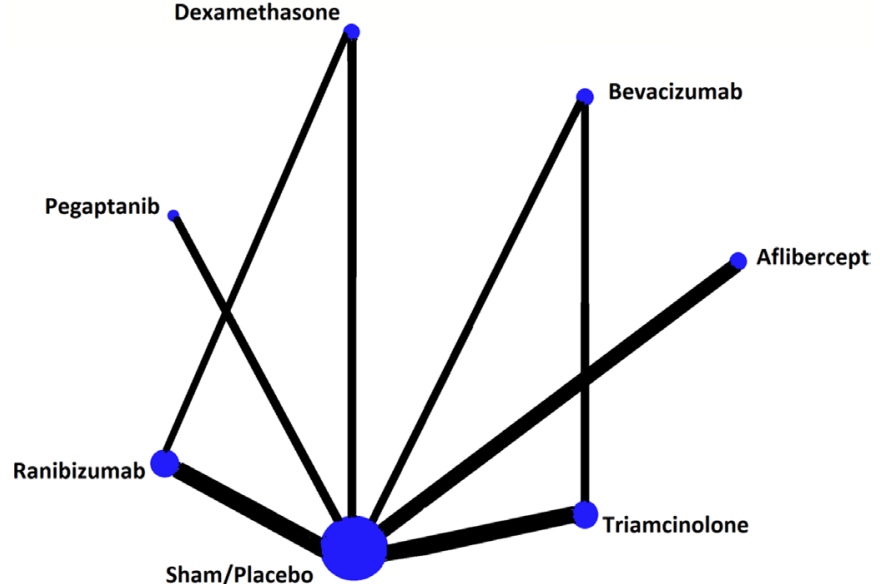

Figure 2 Network graph of all treatment comparisons for all studies. Each node represents one drug. The size of nodes is proportional to the number of randomised participants (sample size). Lines represent direct comparisons within randomised controlled trials, and the width of the lines is proportional to the number of trials comparing each pair of treatments.

(eg, letters gained and VA improvement) as therapeutic effects without consideration of anatomical outcomes and AEs. Therefore, the current systematic review and network meta-analysis was performed to overcome the shortcomings of the previous study and to include data from the latest RCTs. In the present study, we aimed to indirectly compare the clinical efficacy and safety of aflibercept, ranibizumab, bevacizumab, pegaptanib, dexamethasone and triamcinolone for the treatment of ME secondary to CRVO. The clinical efficacy outcomes include best-corrected visual acuity (BCVA) improvement, central retinal thickness (CRT) reduction and the proportion of $\geq 15$ letters gained or lost. The safety outcomes include the proportion of common AEs, such as increased intraocular pressure (IOP), cataracts, neovascular glaucoma and vitreous haemorrhage $(\mathrm{VH})$. We hope that our findings will aid ophthalmologists in choosing the best treatment options for their patients.

\section{METHODS}

This systematic review was performed according to the Preferred Reporting Items for Systematic Reviews and Meta-Analyses (PRISMA) Statement, and the review was conducted and reported according to the PRISMA network meta-analysis (NMA) Checklist of items (see online supplementary appendix 1 ). ${ }^{25}{ }^{26}$ We developed a systematic review protocol and registered it with PROSPERO (CRD42017064076). (Available from http:// www.crd.york.ac.uk/PROSPERO/display_record.asp?ID= CRD42017064076).

\section{Patient and public involvement}

We used secondary data from peer-reviewed published articles, so no patients or public were not involved in this network meta-analysis.

\section{Literature search}

Literature searches were performed using five databases (Embase, Medline, Pubmed Central, Cochrane Library and ClinicalTrials.gov) to identify relevant articles published until the end of March 2017. The following terms were searched in each database: central retinal vein occlusion (CRVO), anti-VEGF agents, corticosteroids and RCTs. The full search strategies are described in online supplementary appendix 2 . In addition, supplementary searches were performed to search for other relevant studies in the WHO International Clinical Trials Registry Platform, Google Scholar and other websites of professional associations. Language or study design restrictions were not used. When titles or abstracts or both fit our search terms, abstracts were reviewed to exclude irrelevant studies (eg, case reports, reviews or experimental treatments). We then carefully read all the remaining articles to determine if they contained data that were applicable to our study.

\section{Article inclusion/exclusion criteria}

In this network meta-analysis, studies were selected based on the following inclusion criteria: (1) The study was an RCT. (2) Ranibizumab, bevacizumab, aflibercept, pegaptanib dexamethasone or triamcinolone was used. (3) Subjects were adults ( $\geq 18$ years) of either sex with ME secondary to CRVO. (4) Studies had to report at least one of the following outcomes: proportions of patients gaining/losing $\geq 15$ letters (three lines) from baseline to 6 or 12 months, the mean change in BCVA from baseline to 6 or 12 months, the mean change in CRT from baseline to 6 or 12 months or the proportions of patients with AEs at 6 or 12 months. Studies that met any of the following criteria were excluded from our meta-analysis: (1) review article, (2) duplicate publication, (3) sufficient information not published (eg, full text not accessible, full text did not contain raw data or inconsistent or erroneous data provided) and (4) subjects with CRVO did not have ME prior to treatment.

\section{Risk of bias assessment}

The included studies were examined independently for biases by two authors using Chapter 8 of the Cochrane Handbook for Systematic Reviews of Interventions. ${ }^{27}$ The following study characteristics were assessed for biases: random sequence generation (selection bias), allocation concealment (selection bias), blinding of participants and personnel (performance bias), blinding of outcome assessment (detection bias), incomplete outcome data (attrition bias), selective reporting (reporting bias) and other factors that contribute to biases (eg, extreme baseline imbalance, study design and trial stopped early because of data-dependent developments). The status of each of the above items was listed as 'yes' to indicate a low risk, 'no' to indicate a high risk or 'unclear' to indicate an unknown risk of bias. 
Table 1 Study characteristics of the 11 randomised controlled trials enrolled

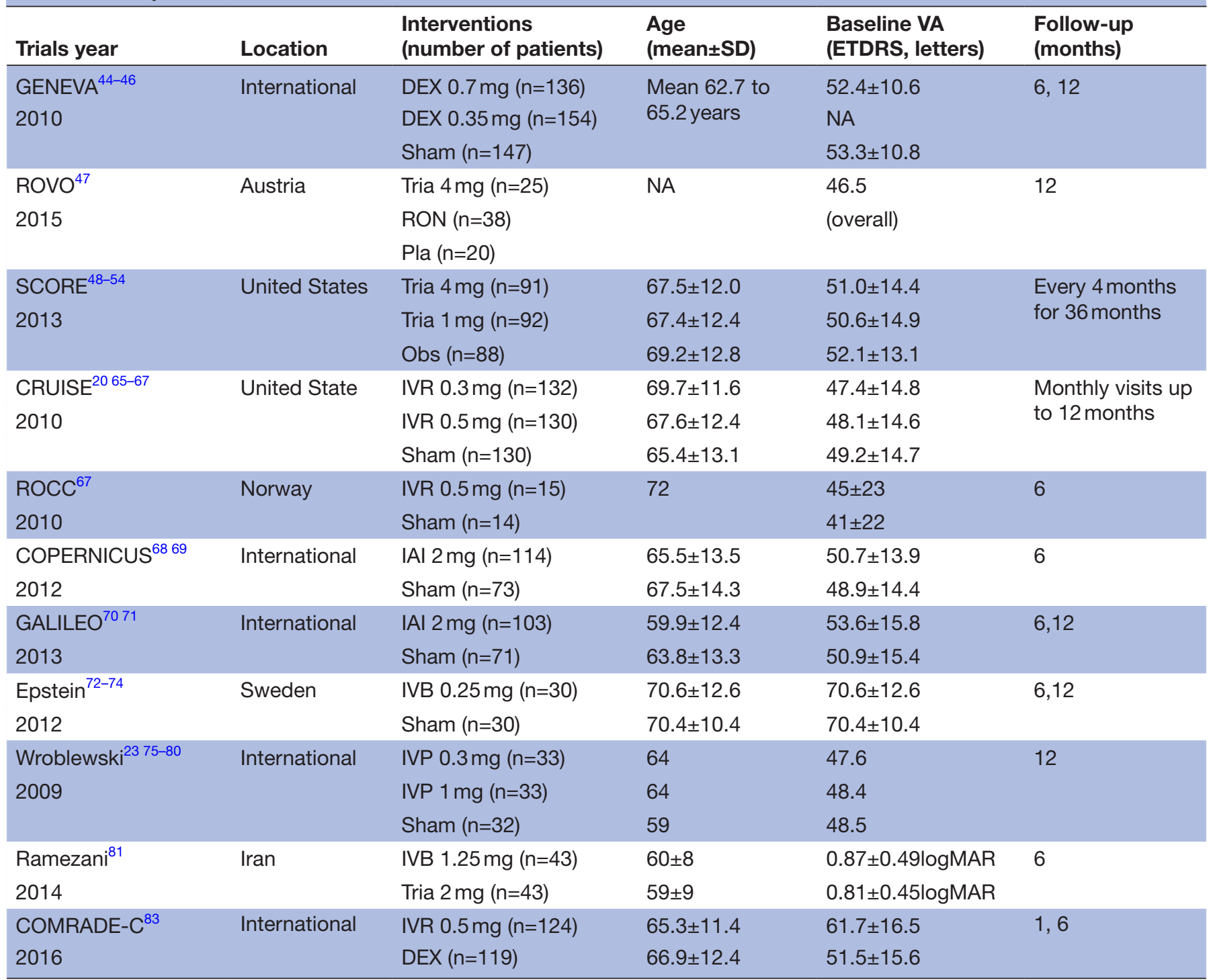

DEX, dexamethasone; IAI, intravitreal aflibercept injections; IVB, intravitreal bevacizumab injections; IVP, intravitreal pegaptanib injections; IVR, intravitreal ranibizumab injections; Obs, observation; Pla, placebo; RON, radial optical neurotomy; Tria, triamcinolone; VA, visual acuity. ETDRS, Early Treatment of Diabetic Retinopathy Study; ROVO, Radial Optic Neurotomy for Central Vein Occlusion; SCORE, Standard Care vs. Corticosteroid for Retinal Vein Occlusion; COMRADE-C, Clinical Efficacy and Safety of Ranibizumab Versus Dexamethasone for Central Retinal Vein Occlusion.

\section{Data extraction}

The following information on study characteristics and clinical treatments were collected from all included studies:

\section{Basic information}

Name of first author, year of publication, design of trial, location of study, setting, follow-up time, clinical trial registration

2. Participants and criteria

Baseline characteristics (age, gender, baseline VA, baseline CRT, duration of ME, etc), inclusion criteria, exclusion criteria

3. Interventions

Different treatment groups and number of patients included

4. Outcomes
Primary outcomes, other outcomes, outcome assessment

Some data that were not reported in articles were published online at ClinicalTrials.gov or other meta-analyses. TQ and MZ carried out search and extracted data. If disagreements occurred, XX would check the data again.

\section{Evaluation indicator}

The indicators of treatment efficacy included the proportions of patients gaining/losing $\geq 15$ letters from baseline to 6 or 12 months and the mean changes in BCVA and CRT. The safety indicators included the proportions of patients with various AEs.

\section{Statistical analyses}

Our analysis classified anti-VEGF agents and corticosteroids used in monotherapy as separate treatment nodes 
Random sequence generation (selection bias)

Allocation concealment (selection bias)

Blinding of participants and personnel (performance bias)

Blinding of outcome assessment (detection bias)

Incomplete outcome data (attrition bias)

Selective reporting (reporting bias)

Other bias

Low risk of bias

Unclear risk of bias

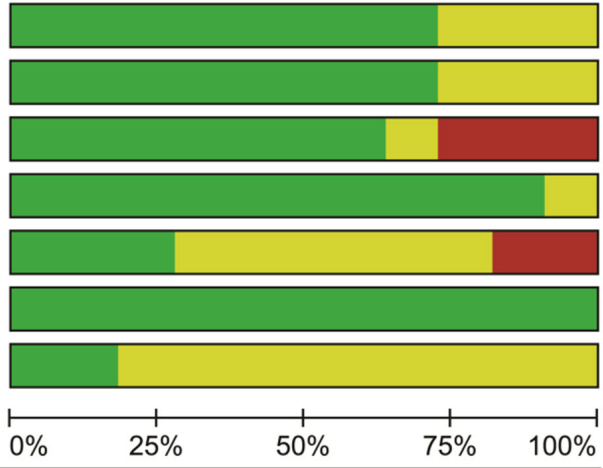

High risk of bias

Figure 3 Risk of bias graph: review authors' judgements about each risk of bias item are presented as percentages across all included studies.

irrespective of their doses: aflibercept, ranibizumab, bevacizumab, pegaptanib, dexamethasone, triamcinolone and placebo or sham (ie, conventional therapy/usual care).

Network meta-analysis allows the integration of data from both direct and indirect evidence, and it can be used to estimate comparisons between pairs of treatments that have not been compared in individual studies. ${ }^{28} 29$ The network meta-analysis was performed within a Bayesian framework by using the Markov Chain Monte Carlo method. ${ }^{30}$ The measures of treatment effects were relative risk (RR) for dichotomous outcomes and the weighted mean difference for continuous outcomes. Bayesian statistical inference provides probability distributions for treatment effect parameters, with $95 \%$ credible intervals (95\% CrI), which can be interpreted as a $95 \%$ probability that the parameter takes a value within the specified range. ${ }^{31} 32$ If 1.0 was not included in the $95 \%$ CrI, the results were considered statistically significant. Consistency analysis could be performed in the presence of similarity and homogeneity, and on this basis, it is possible to rank the effect of different treatment strategies. The higher ranking means the better the treatment is. But when considering the $\mathrm{AE}$, the higher ranking means the more probability of AE. When performing this network meta-analysis, we relied on the assumptions of transitivity and consistency. ${ }^{33}$ The consistency of results was qualitatively examined if sufficient evidence was available. If both direct and indirect evidences existed, node-splitting and pairwise meta-analyses were used to evaluate the inconsistency of direct comparisons in indirect evidences in the network meta-analysis. ${ }^{34}$ In order to analyse the direct and indirect evidences in accordance with the split node, the node-splitting assessment is necessary. And $\mathrm{p}<0.05$ indicates significant heterogeneity in this assessment.

The data of the included studies were analysed using the STATA V.14 (StataCorp LP, College Station, Texas, USA) ${ }^{35}$ and the Aggregate Data Drug Information System (ADDIS V.1.16.8, Drugis, Groningen, NL). ${ }^{36}$

Table 2 Network meta-analysis results in $\geq 15$ letters gained (lower part) and lost (upper part) at 6 months

\begin{tabular}{|c|c|c|c|c|c|c|}
\hline \multirow[b]{2}{*}{ Aflibercept } & \multirow[b]{2}{*}{$\begin{array}{l}1.67 \\
(0.01 \text { to } 321.97)\end{array}$} & \multirow[b]{2}{*}{$\begin{array}{l}8.34 \\
\text { (0.14 to } 746.87)\end{array}$} & \multicolumn{4}{|c|}{ Relative risk $(95 \% \mathrm{Crl})$ in proportions of losing $\geq 15$ letters } \\
\hline & & & $\begin{array}{l}1.61 \\
(0.01,289.03)\end{array}$ & $\begin{array}{l}0.30 \\
(0.00 \text { to } 30.02)\end{array}$ & $\begin{array}{l}8.48 \\
(0.49 \text { to } 176.53)\end{array}$ & $\begin{array}{l}3.42 \\
(0.03 \text { to } 534.31)\end{array}$ \\
\hline $\begin{array}{l}5.67 \\
(0.73 \text { to } 13.87)\end{array}$ & $\begin{array}{l}5.12 \\
\text { (0.38 to } 76.39)\end{array}$ & Dexamethasone & $\begin{array}{l}0.19 \\
(0.00 \text { to } 33.43)\end{array}$ & $\begin{array}{l}0.04 \\
(0.00 \text { to } 0.99)\end{array}$ & $\begin{array}{l}1.01 \\
(0.03 \text { to } 23.86)\end{array}$ & $\begin{array}{l}0.40 \\
(0.00 \text { to } 64.91)\end{array}$ \\
\hline $\begin{array}{l}1.17 \\
(0.14 \text { to } 10.25)\end{array}$ & $\begin{array}{l}1.04 \\
(0.08 \text { to } 16.70)\end{array}$ & $\begin{array}{l}0.20 \\
\text { (0.04 to } 1.07)\end{array}$ & $\begin{array}{l}0.25 \\
(0.02 \text { to } 4.08)\end{array}$ & Ranibizumab & $\begin{array}{l}28.43 \\
(0.95 \text { to } 921.74)\end{array}$ & $\begin{array}{l}11.32 \\
\text { (0.06 to } 2413.4)\end{array}$ \\
\hline $\begin{array}{l}6.97 \\
(1.73 \text { to } 29.70)\end{array}$ & $\begin{array}{l}6.23 \\
\text { (0.76 to } 59.04)\end{array}$ & $\begin{array}{l}1.22 \\
(0.24 \text { to } 5.85)\end{array}$ & $\begin{array}{l}1.54 \\
\text { (0.18 to } 13.37)\end{array}$ & $\begin{array}{l}6.04 \\
(1.15 \text { to } 29.10)\end{array}$ & Sham/Placebo & $\begin{array}{l}0.41 \\
\text { (0.01 to } 20.59)\end{array}$ \\
\hline $\begin{array}{l}1.04 \\
\text { (0.06 to } 13.91)\end{array}$ & $\begin{array}{l}0.94 \\
(0.04 \text { to } 21.87)\end{array}$ & $\begin{array}{l}0.18 \\
\text { (0.01 to } 2.67)\end{array}$ & $\begin{array}{l}0.24 \\
(0.01 \text { to } 4.65)\end{array}$ & $\begin{array}{l}0.88 \\
(0.05 \text { to } 13.74)\end{array}$ & $\begin{array}{l}0.15 \\
(0.01 \text { to } 1.31)\end{array}$ & Triamcinolone \\
\hline
\end{tabular}

\section{Relative risk ( $95 \% \mathrm{Crl}$ ) in proportions of gaining $\geq 15$ letters}

Treatment.

With statistically significant effect.

95\% Crl, $95 \%$ credible intervals. 
Table 3 Ranking based on simulations for gaining $\geq 15$ letters at 6 months

\begin{tabular}{llllllll}
\hline Drug & Rank 1 & Rank 2 & Rank 3 & Rank 4 & Rank 5 & Rank 6 & Rank 7 \\
\hline Aflibercept & 0.22 & 0.31 & 0.27 & 0.15 & 0.03 & 0.01 & 0.00 \\
Bevacizumab & 0.27 & 0.22 & 0.20 & 0.20 & 0.07 & 0.03 & 0.02 \\
Dexamethasone & 0.00 & 0.01 & 0.02 & 0.06 & 0.29 & 0.36 & 0.25 \\
Pegaptanib & 0.02 & 0.03 & 0.05 & 0.12 & 0.35 & 0.18 & 0.24 \\
Ranibizumab & 0.17 & 0.25 & 0.29 & 0.24 & 0.04 & 0.01 & 0.00 \\
Sham/Placebo & 0.00 & 0.00 & 0.00 & 0.02 & 0.14 & 0.39 & 0.46 \\
Triamcinolone & 0.32 & 0.18 & 0.17 & 0.21 & 0.07 & 0.03 & 0.02 \\
\hline
\end{tabular}

The risk of bias graph was drawn using Review Manager V.5.3.5 software. During data analysis, four parallel chains were used and 50000 samples were obtained after a 20 000-sample burn-in in each chain. ${ }^{37}$ Convergence was assessed using the Brooks-Gelman-Rubin method. This method compares within-chain and between-chain variance to calculate the potential scale reduction factor (PSRF). A PSRF close to one indicates that approximate convergence has been reached. ${ }^{38}$

\section{RESULTS}

\section{Literature search results}

The PRISMA flowchart of the selection process of studies included in this network meta-analysis is illustrated in figure 1. In total, 1032 articles were initially identified in our literature searches. Of these, 556 articles were potentially relevant and screened after duplicates had been removed. A title and abstract review eliminated an additional 508 articles. Full-text examinations excluded seven additional articles ${ }^{215} 39-43$ (seven studies) owing to various reasons. Finally, 41 articles $^{20} 23$ 44-82 (11 studies) were included in this systematic review and network meta-analysis. The specific literature of both included and excluded studies is shown in online supplementary appendix 3 .

\section{Characteristics and outcomes of included studies}

Eleven studies comprising 2060 patients with ME secondary to CRVO were included in this meta-analysis. A network graph was constructed to show the network of eligible comparisons for the network meta-analysis (figure 2). Briefly, the follow-up duration was at least 6 months and the patients' ages and gender distributions did not vary significantly among different drug treatment groups. The median sample size was 174 individuals (range 29-437). The main characteristics of the 11 included studies are presented in table 1 . The detailed study results are presented in online supplementary appendix 4 .

\section{Methodological quality of included studies}

The biases of the 11 included studies were assessed using the Cochrane Collaboration's tool as listed in online supplementary appendix 5. Each risk of bias item is expressed as a percentage across all included studies in figure 3. In terms of methodological quality, three trials $(27.3 \%)$ had a high risk of bias.

\section{Efficacy of interventions on the proportions of patients with gaining/losing $\geq 15$ letters at 6 or 12 months}

The improvement of VA was the most important functional measure of treatment efficacy. The proportions of patients gaining $\geq 15$ letters were considered the primary outcome in many included studies. Table 2 shows the RR and $95 \% \mathrm{CrI}$ in the proportions of patients gaining and losing $\geq 15$ letters from baseline for all possible comparisons at 6 months using the consistency model.

In terms of the proportions of patients gaining $\geq 15$ letters, aflibercept (RR 6.97, 95\% CrI 1.73 to 29.70), bevacizumab (RR $6.23,95 \%$ CrI 0.76 to 59.04 ), dexamethasone (RR 1.22, 95\% CrI 0.24 to 5.85), pegaptanib (RR $1.54,95 \% \mathrm{CrI} 0.18$ to 13.37 ), ranibizumab (RR $6.04,95 \%$ CrI 1.15 to 29.10 ) and triamcinolone (RR $6.97,95 \%$ CrI 1.73 to 29.70 ) are more likely to have a positive effect in treatment of CRVO than sham/placebo treatment at 6 months. Among them, aflibercept and ranibizumab were

Table 4 Ranking based on simulations for losing $\geq 15$ letters at 6 months

\begin{tabular}{llllllll}
\hline Drug & Rank 1 & Rank 2 & Rank 3 & Rank 4 & Rank 5 & Rank 6 & Rank 7 \\
\hline Aflibercept & 0.02 & 0.04 & 0.08 & 0.18 & 0.27 & 0.29 & 0.13 \\
Bevacizumab & 0.10 & 0.09 & 0.13 & 0.18 & 0.19 & 0.18 & 0.14 \\
Dexamethasone & 0.37 & 0.24 & 0.18 & 0.12 & 0.06 & 0.03 & 0.00 \\
Pegaptanib & 0.09 & 0.08 & 0.13 & 0.18 & 0.20 & 0.18 & 0.13 \\
Ranibizumab & 0.00 & 0.01 & 0.03 & 0.06 & 0.12 & 0.23 & 0.53 \\
Sham/Placebo & 0.27 & 0.40 & 0.23 & 0.08 & 0.01 & 0.00 & 0.00 \\
Triamcinolone & 0.16 & 0.13 & 0.23 & 0.20 & 0.14 & 0.09 & 0.06 \\
\hline
\end{tabular}


Table 5 Network meta-analysis results in $\geq 15$ letters gained (lower part) and lost (upper part) at 12 months

\begin{tabular}{|c|c|c|c|c|c|c|}
\hline \multirow[b]{2}{*}{ Aflibercept } & \multirow[b]{2}{*}{$\begin{array}{l}3.45 \\
(0.10 \text { to } 91.91)\end{array}$} & \multirow[b]{2}{*}{-} & \multicolumn{4}{|c|}{ Relative risk ( $95 \%$ Crl) in proportions of losing $\geq 15$ letters } \\
\hline & & & - & $\begin{array}{l}0.64 \\
(0.04 \text { to } 10.37)\end{array}$ & $\begin{array}{l}3.35 \\
\text { ( } 0.44 \text { to } 24.39)\end{array}$ & $\begin{array}{l}1.48 \\
(0.09 \text { to } 21.82)\end{array}$ \\
\hline $\begin{array}{l}2.22 \\
(0.34 \text { to } 13.46)\end{array}$ & $\begin{array}{l}2.34 \\
(0.23 \text { to } 23.20)\end{array}$ & Dexamethasone & - & - & - & - \\
\hline $\begin{array}{l}1.45 \\
(0.21 \text { to } 9.28)\end{array}$ & $\begin{array}{l}1.56 \\
(0.15 \text { to } 15.34)\end{array}$ & $\begin{array}{l}0.65 \\
(0.07 \text { to } 5.76)\end{array}$ & - & Ranibizumab & $\begin{array}{l}5.32 \\
(0.68 \text { to } 50.28)\end{array}$ & $\begin{array}{l}2.41 \\
(0.14 \text { to } 41.26)\end{array}$ \\
\hline $\begin{array}{l}3.08 \\
(0.99 \text { to } 8.85)\end{array}$ & $\begin{array}{l}3.26 \\
(0.56 \text { to } 17.47)\end{array}$ & $\begin{array}{l}1.40 \\
(0.32 \text { to } 6.14)\end{array}$ & - & $\begin{array}{l}2.08 \\
(0.45 \text { to } 10.09)\end{array}$ & Sham/Placebo & $\begin{array}{l}0.45 \\
(0.07 \text { to } 2.68)\end{array}$ \\
\hline $\begin{array}{l}0.59 \\
(0.07 \text { to } 4.52)\end{array}$ & $\begin{array}{l}0.63 \\
(0.05 \text { to } 7.43)\end{array}$ & $\begin{array}{l}0.27 \\
\text { (0.03 to } 2.60)\end{array}$ & - & $\begin{array}{l}0.40 \\
(0.04 \text { to } 4.22)\end{array}$ & $\begin{array}{l}0.19 \\
(0.03 \text { to } 1.10)\end{array}$ & Triamcinolone \\
\hline
\end{tabular}

\section{Relative risk $(95 \% \mathrm{Crl})$ in proportions of gaining $\geq 15$ letters}

Treatment.

With statistically significant effect.

significantly superior to the sham/placebo group. Ranibizumab was significantly superior to dexamethasone ( $p=0.04,95 \%$ CrI 0.00 to 0.09$)$ in terms of the proportions of patients losing $\geq 15$ letters. Table 3 shows the rank probabilities of these drugs for the treatment of CRVO according to the proportions of patients gaining $\geq 15$ letters at 6 months, while table 4 shows the rank probabilities of the proportions of patients losing $\geq 15$ letters at 6 months.

Because some specific data were not extracted or reported, the outcomes of the proportions of patients gaining/losing $\geq 15$ letters at 12 months did not involve all drugs. Table 5 shows the RR and $95 \%$ CrI in proportions of patients gaining and losing $\geq 15$ letters from baseline for all possible comparisons at 12 months using the consistency model.

In terms of the proportions of patients gaining $\geq 15$ letters at 12 months, aflibercept (RR 3.08, 95\% CrI 0.99 to 8.85 ), bevacizumab (RR 3.26, 95\% CrI 0.56 to 17.47 ), dexamethasone (RR 1.40, $95 \%$ CrI 0.32 to 6.14), ranibizumab (RR 2.08, 95\% CrI 0.45 to 10.09 ) and triamcinolone (RR $5.21,95 \% \mathrm{CrI}$ 0.91 to 31.67 ) are more likely to have a positive effect in the treatment of CRVO than sham/placebo treatment at 12 months; however, the differences were not significantly different. Table 6 shows the rank probabilities of these drugs for the treatment of CRVO according to the proportions of patients gaining $\geq 15$ letters at 12 months, while table 7 shows the rank probabilities of the proportions of patients losing $\geq 15$ letters at 12 months.

Efficacy of interventions on the mean changes in BCVA from baseline at 6 months

Table 8 shows the mean changes and 95\% CrI of BCVA improvement for all possible comparisons by the network meta-analysis using the consistency model. Patients treated with aflibercept (RR 17.88, 95\% CrI 7.59 to 29.11), bevacizumab (RR 19.32, 95\% CrI 5.17 to 33.11) and ranibizumab (RR 13.78, 95\% CrI 1.58 to 24.91) showed greater improvements in BCVA than those treated with sham/ placebo group at 6 months, and the differences were significant. Triamcinolone ( $\mathrm{RR} 7.48,95 \% \mathrm{CrI}-6.05$ to 20.78) was also superior to sham injection, but the difference was not significant. Overall, patients treated with antiVEGF agents (aflibercept, ranibizumab or bevacizumab) had a higher probability of improvement in BCVA than those treated with corticosteroid agents (triamcinolone or dexamethasone).

Table 6 Ranking based on simulations for gaining $\geq 15$ letters at 12 months

\begin{tabular}{llllllll}
\hline Drug & Rank 1 & Rank 2 & Rank 3 & Rank 4 & Rank 5 & Rank 6 \\
\hline Aflibercept & 0.12 & 0.33 & 0.34 & 0.15 & 0.04 & 0.01 & 0.05 \\
Bevacizumab & 0.24 & 0.29 & 0.20 & 0.15 & 0.20 & 0.39 & 0.23 \\
Dexamethasone & 0.02 & 0.05 & 0.10 & 0.35 & 0.15 & 0.08 \\
Ranibizumab & 0.06 & 0.13 & 0.22 & 0.07 & 0.31 & 0.61 \\
Sham/Placebo & 0.00 & 0.00 & 0.01 & 0.08 & 0.03 & 0.02 \\
Triamcinolone & 0.55 & 0.20 & 0.12 & & & \\
\hline
\end{tabular}


Table 7 Ranking based on simulations for losing $\geq 15$ letters at 12 months

\begin{tabular}{llllll}
\hline Drug & Rank 1 & Rank 2 & Rank 3 & Rank 4 & Rank 5 \\
\hline Aflibercept & 0.05 & 0.10 & 0.22 & 0.35 & 0.27 \\
Bevacizumab & 0.47 & 0.18 & 0.15 & 0.11 & 0.08 \\
Ranibizumab & 0.03 & 0.05 & 0.13 & 0.28 & 0.52 \\
Sham/Placebo & 0.37 & 0.50 & 0.12 & 0.01 & 0.00 \\
Triamcinolone & 0.09 & 0.17 & 0.38 & 0.24 & 0.12 \\
\hline
\end{tabular}

Table 9 shows the rank probability of these drugs for the treatment of CRVO according to the BCVA improvement at 6 months.

Efficacy of interventions on mean changes in CRT from baseline at 6 months

The CRT represents anatomic changes in the fovea after treatment. As certain studies did not report CRT changes after treatment, the evaluation of CRT only involved ranibizumab, dexamethasone and sham injections. Intravitreal ranibizumab injections showed greater reduction in CRT than both sham injection (RR $-156.80,95 \%$ CrI -452.68 to 144.63$)$ and dexamethasone (RR -205.30, $95 \% \mathrm{CrI}-470.88$ to 64.62$)$. Table 10 shows the rank probability of these three drugs for the treatment of CRVO according to CRT reductions at 6 months.

\section{Adverse events}

Many AEs were reported after drug treatment in the 11 studies, which comprised 2060 patients (table 11). The most common ocular $\mathrm{AE}$ reported in more than two studies that could be compared by network meta-analysis were increased IOP, cataracts, VH and retinal tear.

\section{Consistency analysis of network model}

Based on direct versus indirect evidence, we compared the effect estimate twice using node-splitting, considering that direct and indirect evidences existed together. The first was the comparison of ranibizumab, dexamethasone and sham/placebo, while the second was bevacizumab, triamcinolone and sham/placebo. Table 12 shows the comparisons of the estimated quantiles for the direct and indirect evidence, as well as the combined evidence. No inconsistencies were observed $(p>0.05)$. These data suggest that our model is relatively robust.

\section{Benefit-risk analysis between anti-VEGF agents and dexamethasone}

For the purpose of the proposed methods, benefit-risk analysis is defined as the quantitative synthesis of drug efficacy (or effectiveness) and AE profile. ${ }^{83}$ Based on the existing data from the included studies, benefit-risk analysis could be performed if efficacy outcomes and safety outcomes were both reported at the same time. When considering gaining $\geq 15$ letters at 6 months as a benefit index and increased IOP as a risk index, aflibercept and ranibizumab were superior to dexamethasone in the treatment of ME secondary to CRVO (figure 4). When considering gaining $\geq 15$ letters at 6 months as a benefit index and cataracts as a risk index, ranibizumab exhibited a greater benefit of visual improvement as well as a higher risk of cataracts than dexamethasone (figure 5).

\section{Benefit- risk analysis of aflibercept versus ranibizumab}

Aflibercept and ranibizumab are the two most widely used anti-VEGF agents in the treatment of CRVO worldwide. However, there are few head-to-head RCTs comparing the

Table 8 Network meta-analysis results in BCVA changes (lower part) and CRT changes (upper part) at 6 months

\section{Weighted mean difference $(95 \% \mathrm{Crl})$ in CRT change to $\mathrm{mm}$}

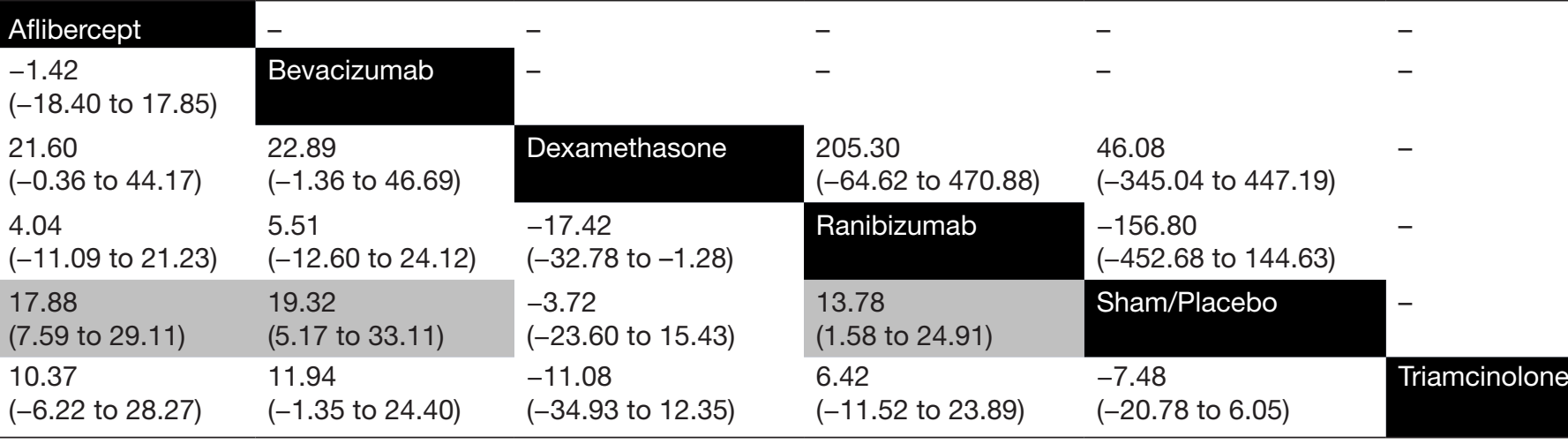

\section{Weighted mean difference (95\% Crl) in BCVA changes, letters}

Treatment.

With statistically significant effect. 
Table 9 Ranking based on simulations for BCVA changes from baseline at 6 months

\begin{tabular}{lllllll} 
Drug & Rank 1 & Rank 2 & Rank 3 & Rank 4 & Rank 5 & Rank 6 \\
\hline Aflibercept & 0.34 & 0.45 & 0.16 & 0.04 & 0.01 & 0.00 \\
Bevacizumab & 0.54 & 0.28 & 0.14 & 0.02 & 0.01 & 0.00 \\
Dexamethasone & 0.01 & 0.01 & 0.02 & 0.07 & 0.19 & 0.70 \\
Ranibizumab & 0.10 & 0.21 & 0.53 & 0.14 & 0.02 & 0.00 \\
Sham/Placebo & 0.00 & 0.00 & 0.01 & 0.06 & 0.68 & 0.25 \\
Triamcinolone & 0.01 & 0.05 & 0.14 & 0.66 & 0.10 & 0.04 \\
\hline
\end{tabular}

95\% Crl, 95\% credible intervals; BCVA, best-corrected visual acuity; CRT, central retinal thickness.

efficacy and safety of aflibercept and ranibizumab directly. Gaining $\geq 15$ letters at 6 months was considered a benefit index; and increased IOP, vitreous haemorrhage, and retinal tear were considered risk indexs. Thus, aflibercept exhibited slightly better visual improvement and a lower risk of the latter three $\mathrm{AE}$ than ranibizumab (figure 6).

\section{DISCUSSION}

Intravitreal corticosteroids ${ }^{12}$ (triamcinolone or dexamethasone) and intravitreal anti-VEGF drugs ${ }^{84} 85$ are both therapeutic options for CRVO patients despite their limitations. It is important that comparisons of the efficacy and safety of intravitreal anti-VEGF injection and intravitreal corticosteroids are needed in patients with ME secondary to CRVO.

In terms of the proportions of patients gaining $\geq 15$ letters at 6 months, our results showed that only aflibercept and ranibizumab had a significantly better efficacy than the sham/placebo group. Between the four main anti-VEGF agents and the two corticosteroids, our results showed no evidence of differences in effectiveness at both 6 and 12 months. According to the rank probability of the existing data, aflibercept, bevacizumab and triamcinolone are the best three drugs, with no statistical significance, in gaining $\geq 15$ letters at 6 and 12 months. However, bevacizumab and triamcinolone were used off-label and lacked safety data. Therefore, aflibercept would be considered the first choice to improve $\mathrm{VA}$ in the treatment of $\mathrm{ME}$ secondary to CRVO. Aflibercept targets a wider range of cytokines and may have a stronger binding affinity, ${ }^{86}$ which could explain the greater efficacy in visual improvement, than ranibizumab, bevacizumab and pegaptanib. Unlike corticosteroids, anti-VEGF could decrease the vitreal levels of VEGF. Aflibercept and ranibizumab exhibited significantly better efficacy at 6 months but not at 12 months, indicating that the effects of aflibercept and

Table 10 Ranking based on simulations for CRT changes from baseline at 6 months

\begin{tabular}{llll}
\hline Drug & Rank 1 & Rank 2 & Rank 3 \\
\hline Dexamethasone & 0.61 & 0.34 & 0.05 \\
Ranibizumab & 0.01 & 0.16 & 0.83 \\
Sham/Placebo & 0.37 & 0.51 & 0.12 \\
\hline
\end{tabular}

ranibizumab were less obvious than the effects of the sham/placebo group as the follow-up time progressed.

In terms of the proportion of patients that lost $\geq 15$ letters at 6 or 12 months, the pooled result showed that only ranibizumab was superior to dexamethasone, with a significant difference at 6 months. Although no significant difference was found among the other drug treatment groups, anti-VEGF agents showed a tendency toward better efficacy in visual improvement than corticosteroids did. Among the anti-VEGF agents, ranibizumab had the lowest risk of patients losing $\geq 15$ letters.

Apart from the $\geq 15$ letters gained or lost, BCVA changes from baseline could reflect visual recovery. At 6 months, aflibercept, bevacizumab and ranibizumab showed a greater improvement in BCVA than the sham/ placebo group, with a statistically significant difference. The results support the efficacy of anti-VEGF agents for VA improvement to some extent, which is consistent with the aforementioned results of $\geq 15$ letters gained or lost. In the case of visual improvement, anti-VEGF agents, especially ranibizumab and aflibercept, were better than corticosteroids.

CRT, an anatomical index reflecting macular, was also considered as an important outcome to estimate the efficacy of these drugs. Only three RCTs reported a CRT reduction. According to the outcomes reported, ranibizumab afforded more reduction in CRT at 6 months than dexamethasone, and bevacizumab afforded more reduction than triamcinolone. As for intravitreal anti-VEGF injections, the resolution of exudative fluid and retinal oedema is important for the favourable treatment of BCVA. $^{87}$

A low incidence of AEs should also be considered besides the better efficacy of different drug treatments. In this network meta-analysis, increased IOP, cataracts, VH and retinal tear are the four most frequently reported AEs from the included studies. More reported data can lead to more accurate analyses. As shown in table 11, dexamethasone has a higher risk of increased IOP compared with that of aflibercept and ranibizumab. In contrast, ranibizumab was associated with a higher probability of cataracts than dexamethasone. Cataracts are associated with injection frequency, and dexamethasone needs fewer injections than anti-VEGF agents. Gu et al reported that the advantages of dexamethasone are fewer number 
Table 11 Main adverse events after drug treatment reported according to the included studies

\begin{tabular}{|c|c|c|c|c|c|c|}
\hline Drugs & Aflibercept & Ranibizumab & Bevacizumab & Dexamethasone & Triamcinolone & Sham/Placebo \\
\hline \multicolumn{7}{|l|}{ Adverse events } \\
\hline IOP increased & $10 / 104$ & $7 / 124$ & & $78 / 252$ & $8 / 125$ & $6 / 235$ \\
\hline Neovascular glaucoma & $0 / 114$ & $0 / 129$ & & & $3 / 25$ & $7 / 223$ \\
\hline Conjunctival haemorrhage & 9/104 & $16 / 125$ & & $13 / 119$ & & $3 / 68$ \\
\hline Eye irritation & $3 / 104$ & & & & & $7 / 68$ \\
\hline Eye pain & $12 / 104$ & $15 / 124$ & & $15 / 119$ & & $3 / 68$ \\
\hline Retinal haemorrhage & $0 / 114$ & & & & & $2 / 74$ \\
\hline Retinal tear & $0 / 114$ & $0 / 15$ & & & & $2 / 88$ \\
\hline Iris neovascularisation & $0 / 114$ & $0 / 124$ & & $9 / 119$ & & $2 / 74$ \\
\hline
\end{tabular}

IOP, intraocular pressure.

of injections and long-term efficacy, while the advantages of ranibizumab include lower incidence of increased $\mathrm{IOP}^{88}$ which is similar to the results of our pooled data. A head-to-head trial called comparison of ranibizumab PRN versus single-dose dexamethasone for branch retinal vein occlusion (COMRADE-B) demonstrated that elevated IOP occurred more frequently with dexamethasone than with ranibizumab treatment, similar to Branch Retinal Vein Occlusion (BRVO). ${ }^{89}$ In addition, aflibercept showed lower incidence of $\mathrm{VH}$ and ranibizumab showed lower incidence of retinal tear. AEs mainly arise from the disease process itself or as a result of the side effects during the course of treatment. Intravitreal anti-VEGF or corticosteroid injections and traumatic procedures sometimes cause AEs such as endophthalmitis. Safety is as important as efficacy after treatment, and both must be considered comprehensively in the selection of drugs for CRVO.

When comparing ranibizumab, dexamethasone and sham/placebo, as well as bevacizumab, triamcinolone and sham/placebo, node-splitting and pairwise meta-analysis could be used to estimate the efficacy based on direct versus indirect evidence. If direct and indirect evidence existed together, the consistencies could be tested. Since no inconsistencies were observed in this network meta-analysis, we performed sensitivity analysis of the comparison of random and fixed effects models, which was more accurate. ${ }^{34}$ The unchanged outcome suggests that our model was robust according to known data, and therefore, the results of this network meta-analysis would be useful in clinical practice.

Table 12 Node-splitting meta-analysis of two comparison

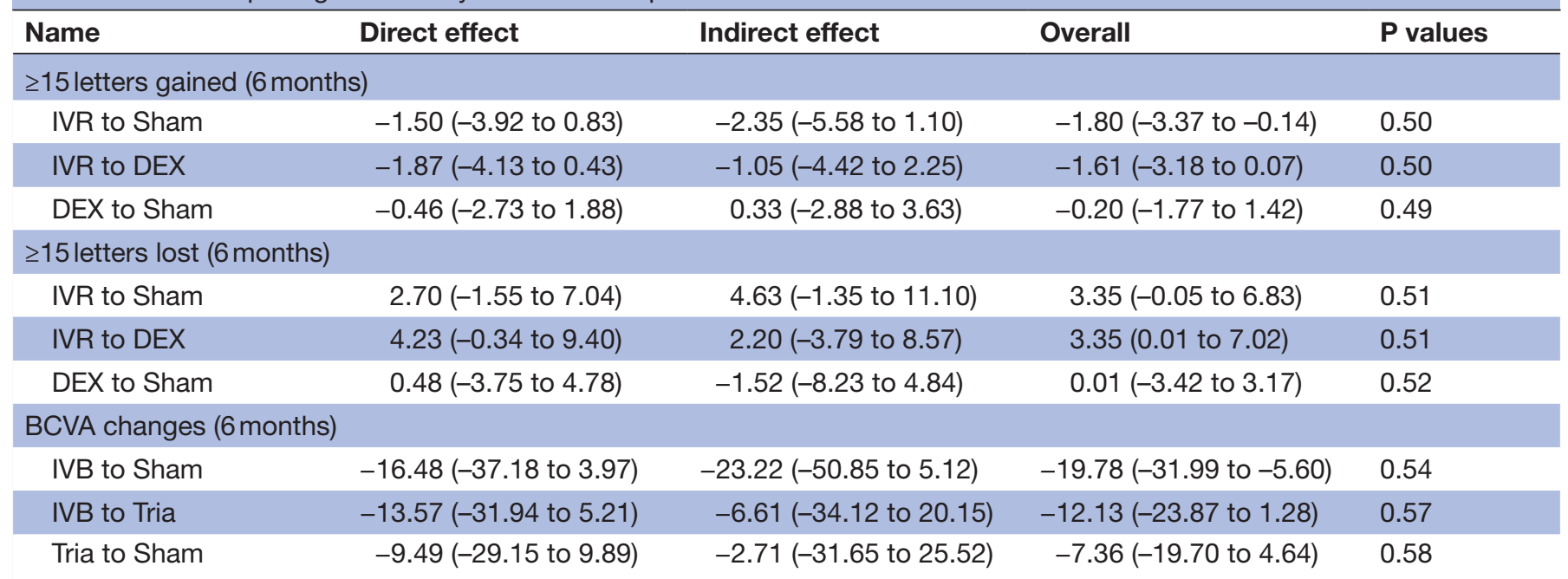

BCVA, mean change in best-corrected visual acuity; DEX, dexamethasone; IVB, intravitreal bevacizumab; IVR, intravitreal ranibizumab; Tria, triamcinolone. 
Benefit-Risk summary: Aflibercept vs Dexamethasone
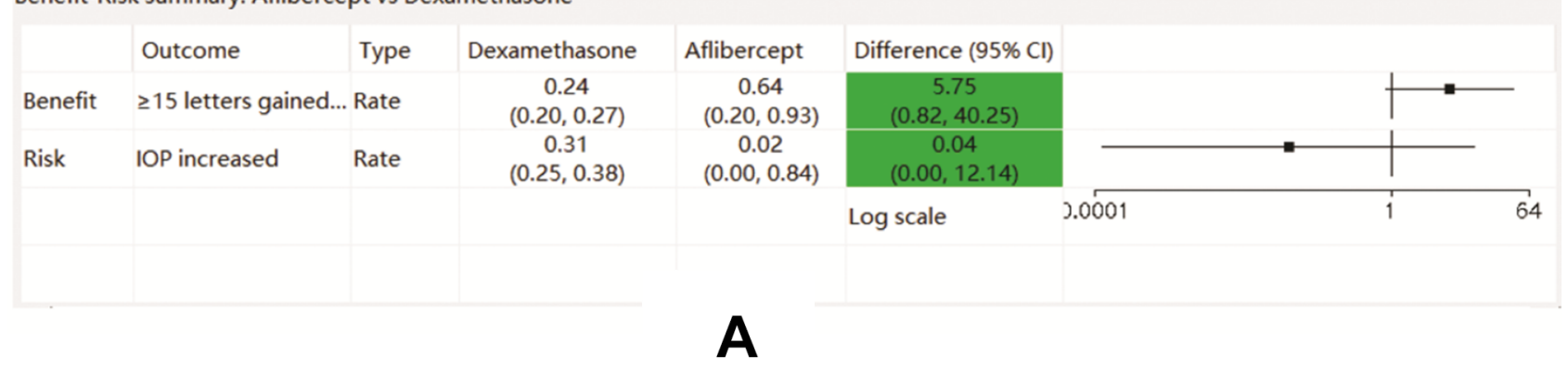

Benefit-Risk summary: Ranibizumab vs Dexamethasone

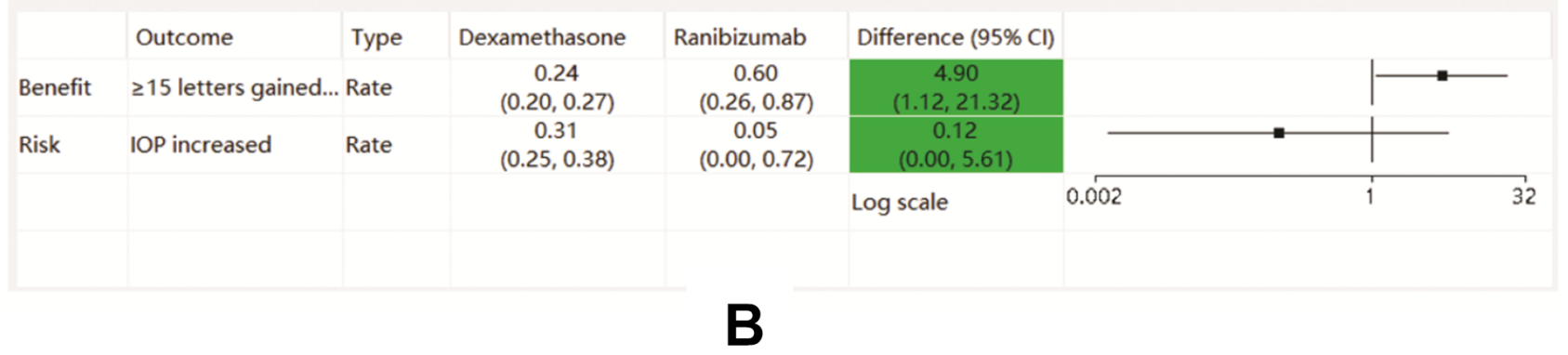

Figure 4 Benefit-risk analysis of aflibercept and ranibizumab versus dexamethasone considering gaining $\geq 15$ letters and increased intraocular pressure (IOP): (A) aflibercept versus dexamethasone; (B) ranibizumab versus dexamethasone. Key benefit-risk summary with embedded relative effect forest plot. The colour in the 'difference' column indicates whether the point estimate favours dexamethasone (red) or aflibercept/ranibizumab (green). The symbol in the forest plot indicates whether the logarithmic (square) scale is used.

As mentioned above, both dexamethasone and ranibizumab have their own advantages and disadvantages. ${ }^{88}$ Broadly speaking, each drug has benefits and risks; therefore, estimating benefits and risks consistently is necessary. Although anti-VEGF agents can avoid the increased IOP caused by dexamethasone, the high risk of developing cataracts after anti-VEGF treatment, especially ranibizumab, cannot be ignored.

Aflibercept and ranibizumab are the two, on-label maximum dosage drugs recently approved in Europe and America. According to the data of benefit-risk analysis between the two drugs from the included studies, aflibercept had a slight advantage over ranibizumab. However, this does not mean that aflibercept is effective for all patients. Patients need to choose medications according to their actual situation. During our clinical practice, some patients were not responsive to anti-VEGF agents, but instead responded to dexamethasone.

Considering that intravitreal anti-VEGF agents are expensive, intravitreal corticosteroids should be considered to reduce the overall treatment cost. However, care should be taken when using these treatments because elevated IOP is seen more frequently with corticosteroid therapy than with anti-VEGF therapy, as demonstrated by our network meta-analysis. Regardless of the treatment administered, all patients with CRVO should be closely monitored for IOP changes and VA.

This is the second network meta-analysis providing an indirect comparison of drugs to treat ME secondary to CRVO, and our study possesses several strengths when compared with previous systematic reviews. ${ }^{24}$ First, our meta-analysis included the most recent reports, analysing

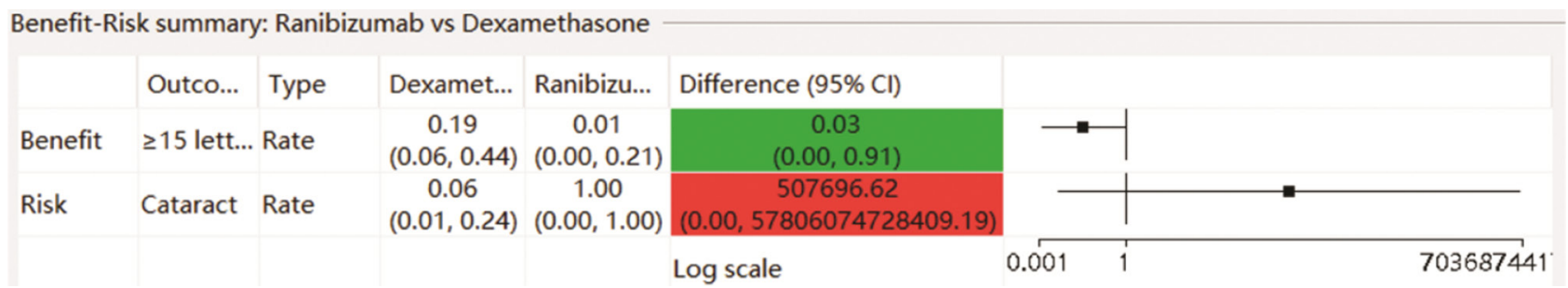

Figure 5 Benefit-risk analysis of ranibizumab versus dexamethasone considering gaining $\geq 15$ letters and cataracts. Key benefit-risk summary table with embedded relative effect forest plot. The colour in the 'difference' column indicates whether the point estimate favours dexamethasone (red) or ranibizumab (green). The symbol in the forest plot indicates whether the logarithmic (square) scale is used. 
Benefit-Risk summary: Aflibercept vs Ranibizumab

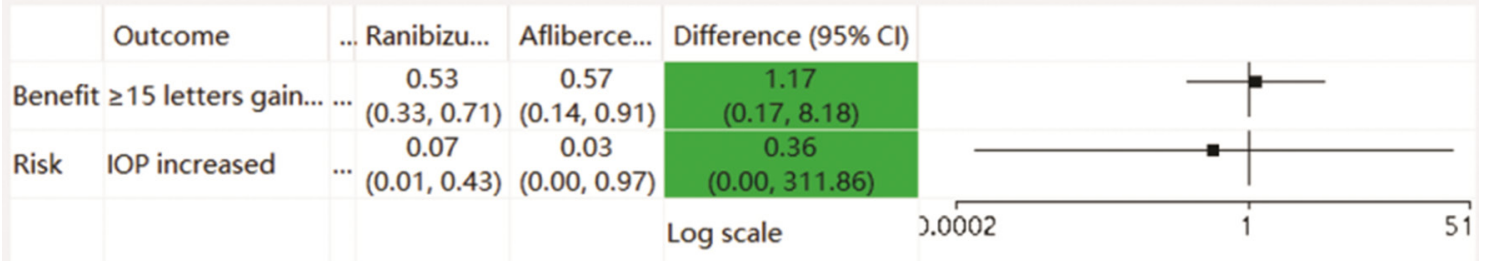

A

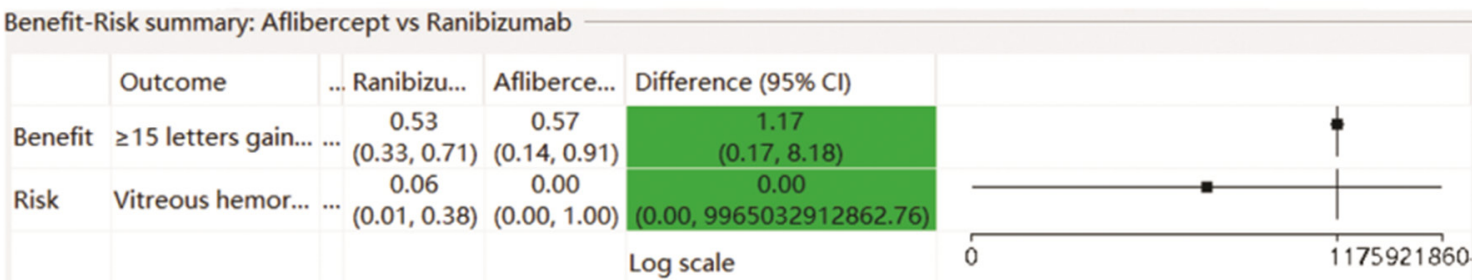

B

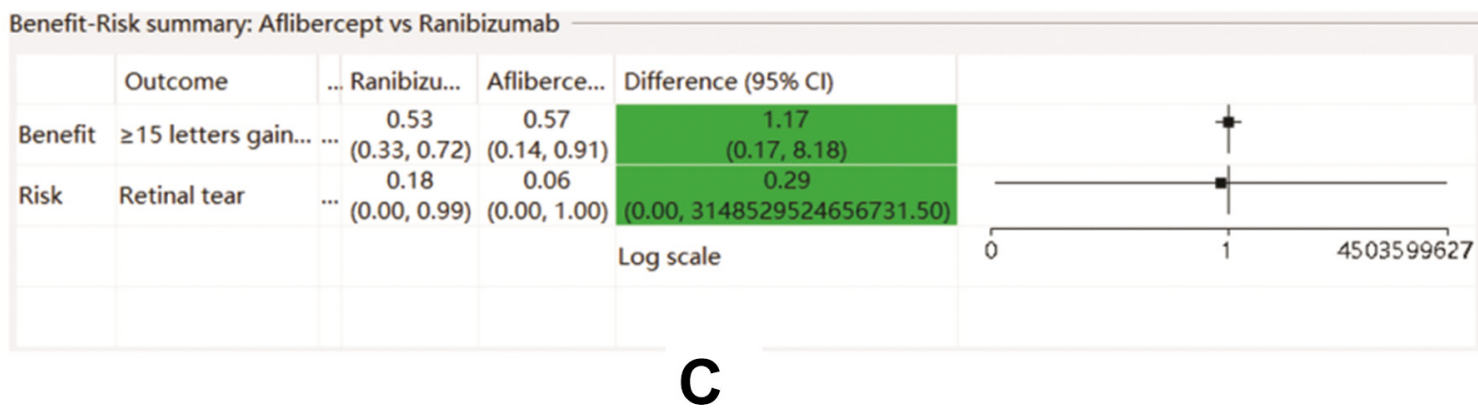

Figure 6 Benefit-risk analysis of aflibercept versus ranibizumab considering gaining $\geq 15$ letters at 6 months and the three main adverse events: (A) increased intraocular pressure (IOP); (B) vitreous haemorrhage; (C) retinal tear. Key benefit-risk summary table with embedded relative effect forest plot. The colour in the 'difference' column indicates whether the point estimate favours ranibizumab (red) or aflibercept (green). The symbol in the forest plot indicates whether the logarithmic (square) scale is used.

studies published as late as 1 May 2017. Second, we performed a comprehensive comparison of aflibercept, ranibizumab, bevacizumab, pegaptanib, dexamethasone and triamcinolone treatment using strict inclusion and exclusion criteria. Third, the 12-month follow-up time point was also considered in addition to 6 months, because the outcome at 12 months could better show the duration of efficacy after treatment.

Although the results of this work may be important for clinical treatment, there are certain limitations that need to be considered. First, our data contained some biases, which may have influenced our results. Second, more detailed data at long-term follow-up time points (eg, 24 months) are required to improve the accuracy and robustness of our findings for clinical applications. Third, the details of AEs were not always reported in each study, and the data available can only indicate the relative safety of every intervention for CRVO. To assess the efficacy of these treatments more accurately, additional high-quality RCTs with comprehensive safety data will be necessary.

Head-to-head trials comparing ranibizumab, aflibercept, bevacizumab, pegaptanib, dexamethasone and triamcinolone are needed. Further long-term, prospective studies are needed to examine and compare the safety and efficacy of CRVO-associated ME treatment strategies. Including data from future studies in subsequent meta-analyses will improve conclusion accuracy and robustness and provide better clinical guidance. In addition, as patients can be concerned about the cost of treatment, clinicians may prefer aflibercept because it requires fewer injections. ${ }^{24}$

\section{CONCLUSION}

Our analysis confirms that anti-VEGF agents have more advantages than corticosteroids in the treatment of ME 
secondary to CRVO. A higher proportion of the patients who received intravitreal anti-VEGF injections gained $\geq 15$ letters than those treated with corticosteroids at both 6 and 12 months. Among these anti-VEGF agents, aflibercept and ranibizumab were the best drugs for BCVA improvement and CRT reduction. In terms of $\mathrm{AE}$, the results of network meta-analysis showed that (1) dexamethasone was associated with a higher risk of increased IOP than aflibercept and ranibizumab, (2) ranibizumab had a higher probability of cataract formation than dexamethasone, (3) aflibercept exhibited superiority in terms of low incidence of $\mathrm{VH}$ and (4) ranibizumab exhibited superiority in terms of low incidence of retinal tear. Aflibercept was shown to have a slight advantage over ranibizumab by benefit-risk analysis, but with no statistical difference. More high-quality RCTs will be necessary as the results of this study provide only a reference for clinicians. Each patient must be evaluated individually for the appropriate treatment regimen.

\section{Acknowledgements The authors thank the researchers whose studies were} included in this network meta-analysis and provided useful data to us.

Contributors TQ: study conception, study design, data collection, data analysis, manuscript writing and final manuscript approval; MZ: study design, data collection and critical manuscript revision; YW: statistical analysis; MXL: statistical analysis; XX: study conception, study design, critical manuscript revision and final manuscript approval.

Funding This study was funded by the National Natural Science Foundation of China (Grant No. 81800878) and Interdisciplinary Program of Shanghai Jiao Tong University (Grant No.YG2017QN24).

Competing interests None declared.

Patient consent Not required.

Provenance and peer review Not commissioned; externally peer reviewed.

Data sharing statement Extra data can be accessed via the Dryad data repository at http://datadryad.org/withthedoi:10.5061/dryad.p1qq2r1.

Open access This is an open access article distributed in accordance with the Creative Commons Attribution Non Commercial (CC BY-NC 4.0) license, which permits others to distribute, remix, adapt, build upon this work non-commercially, and license their derivative works on different terms, provided the original work is properly cited, appropriate credit is given, any changes made indicated, and the use is non-commercial. See: http://creativecommons.org/licenses/by-nc/4.0/.

\section{REFERENCES}

1. Rogers S, Mclntosh RL, Cheung N, et al. The prevalence of retinal vein occlusion: pooled data from population studies from the United States, Europe, Asia, and Australia. Ophthalmology 2010;117:313-9.

2. Spaide RF, Chang LK, Klancnik JM, et al. Prospective study of intravitreal ranibizumab as a treatment for decreased visual acuity secondary to central retinal vein occlusion. Am J Ophthalmol 2009;147:298-306.

3. Mclntosh RL, Rogers SL, Lim L, et al. Natural history of central retinal vein occlusion: an evidence-based systematic review. Ophthalmology 2010;117:1113-23.

4. Hayreh SS, Podhajsky PA, Zimmerman MB. Natural history of visual outcome in central retinal vein occlusion. Ophthalmology 2011;118:119-33.

5. Eye Disease Case-Control Study Group. Risk factors for central retinal vein occlusion. Arch Ophthal 1996;114:545-54.

6. McAllister IL. Central retinal vein occlusion: a review. Clin Exp Ophthalmol 2012;40:48-58.

7. Hayreh SS, Zimmerman MB, Podhajsky P. Incidence of various types of retinal vein occlusion and their recurrence and demographic characteristics. Am J Ophthalmol 1994;117:429-41.

8. Cugati S, Wang JJ, Rochtchina E, et al. Ten-year incidence of retinal vein occlusion in an older population: the Blue Mountains Eye Study. Arch Ophthalmol 2006;124:726-32.
9. Klein R, Moss SE, Meuer SM, et al. The 15-year cumulative incidence of retinal vein occlusion: the Beaver Dam Eye Study. Arch Ophthalmol 2008;126:513-8.

10. Clarkson JG, Chuang E, Gass D, et al. Evaluation of grid pattern photocoagulation for macular edema in central vein occlusion. The Central Vein Occlusion Study Group M report. Ophthalmology 1995;102:1425-33.

11. Cooney MJ, Fekrat S, Finkelstein D. Current concepts in the management of central retinal vein occlusion. Curr Opin Ophthalmol 1998;9:47-50.

12. Laouri $\mathrm{M}$, Chen $\mathrm{E}$, Looman $\mathrm{M}$, et al. The burden of disease of retinal vein occlusion: review of the literature. Eye 2011;25:981-8.

13. Ip MS, Gottlieb JL, Kahana A, et al. Intravitreal triamcinolone for the treatment of macular edema associated with central retinal vein occlusion. Arch Ophthalmol 2004;122:1131-6.

14. Cekiç $\mathrm{O}$, Chang S, Tseng JJ, et al. Intravitreal triamcinolone treatment for macular edema associated with central retinal vein occlusion and hemiretinal vein occlusion. Retina 2005;25:846-50.

15. Ramezani A, Entezari M, Moradian S, et al. Intravitreal triamcinolone for acute central retinal vein occlusion; a randomized clinical trial. Graefes Arch Clin Exp Ophthalmol 2006;244:1601-6.

16. Kuppermann BD, Blumenkranz MS, Haller JA, et al. Randomized controlled study of an intravitreous dexamethasone drug delivery system in patients with persistent macular edema. Arch Ophthalmol 2007;125:309-17.

17. Ferrara N, Davis-Smyth T. The biology of vascular endothelial growth factor. Endocr Rev 1997;18:4-25.

18. Vinores SA, Derevjanik NL, Ozaki H, et al. Cellular mechanisms of blood-retinal barrier dysfunction in macular edema. Doc Ophthalmol 1999;97:217-28.

19. Aiello LP, Avery RL, Arrigg PG, et al. Vascular endothelial growth factor in ocular fluid of patients with diabetic retinopathy and other retinal disorders. N Engl J Med 1994;331:1480-7.

20. Heier JS, Campochiaro PA, Yau L, et al. Ranibizumab for macular edema due to retinal vein occlusions: long-term follow-up in the HORIZON trial. Ophthalmology 2012;119:802-9.

21. Zhang H, Liu ZL, Sun $\mathrm{P}$, et al. Intravitreal bevacizumab for treatment of macular edema secondary to central retinal vein occlusion: eighteen-month results of a prospective trial. J Ocul Pharmacol Ther 2011;27:615-21.

22. Saishin $Y$, Ito $Y$, Fujikawa $M$, et al. Comparison between ranibizumab and aflibercept for macular edema associated with central retinal vein occlusion. Jpn J Ophthalmol 2017;61:67-73.

23. Wroblewski JJ, Wells JA, Adamis AP, et al. Pegaptanib sodium for macular edema secondary to central retinal vein occlusion. Arch Ophthalmol 2009;127:374-80.

24. Ford JA, Shyangdan D, Uthman OA, et al. Drug treatment of macular oedema secondary to central retinal vein occlusion: a network metaanalysis. BMJ Open 2014;4:e005292.

25. Moher D, Liberati A, Tetzlaff J, et al. Preferred reporting items for systematic reviews and meta-analyses: the PRISMA statement. PLoS Med 2009;6:e1000097.

26. Hutton B, Salanti G, Caldwell DM, et al. The PRISMA extension statement for reporting of systematic reviews incorporating network meta-analyses of health care interventions: checklist and explanations. Ann Intern Med 2015;162:777-84.

27. Higgins JPT, Altman DG, Sterne JAC. Chapter 8: Assessing risk of bias in included studies. Cochrane Handbook for Systematic Reviews of Interventions Version 5.1.0: The Cochrane Collaboration, 2011.

28. Cipriani A, Higgins JP, Geddes JR, et al. Conceptual and technical challenges in network meta-analysis. Ann Intern Med 2013;159:130-7.

29. Catalá-López F, Tobías A, Cameron C, et al. Network meta-analysis for comparing treatment effects of multiple interventions: an introduction. Rheumatol Int 2014;34:1489-96.

30. Salanti G, Higgins JP, Ades AE, et al. Evaluation of networks of randomized trials. Stat Methods Med Res 2008;17:279-301.

31. Lu G, Ades AE. Combination of direct and indirect evidence in mixed treatment comparisons. Stat Med 2004;23:3105-24.

32. Caldwell DM, Ades AE, Higgins JP. Simultaneous comparison of multiple treatments: combining direct and indirect evidence. BMJ 2005;331:897-900.

33. Catalá-López F, Hutton B, Moher D. The Transitive Property Across Randomized Controlled Trials: If $B$ Is Better Than A, and $C$ Is Better Than B, Will C Be Better Than A? Revista Española de Cardiología 2014;67:597-602.

34. Dias S, Welton NJ, Caldwell DM, et al. Checking consistency in mixed treatment comparison meta-analysis. Stat Med 2010;29(78):932-44.

35. Chaimani A, Higgins JP, Mavridis D, et al. Graphical tools for network meta-analysis in STATA. PLoS One 2013;8:e76654. 
36. van Valkenhoef G, Tervonen T, Zwinkels T, et al. ADDIS: a decision support system for evidence-based medicine. Decis Support Syst 2013;55:459-75.

37. Gelman A, Rubin DB. Inference from iterative simulation using multiple sequences. Statistical Science 1992;7:457-72.

38. Brooks SP, Gelman A. General methods for monitoring convergence of iterative simulations. Journal of computational and graphical statistics 1998; 7:434-55.

39. Larsen M, Waldstein SM, Boscia F, et al. Individualized Ranibizumab Regimen Driven by Stabilization Criteria for Central Retinal Vein Occlusion: Twelve-Month Results of the CRYSTAL Study. Ophthalmology 2016;123:1101-11.

40. Wang HY, Li X, Wang YS, et al. Intravitreal injection of bevacizumab alone or with triamcinolone acetonide for treatment of macular edema caused by central retinal vein occlusion. Int J Ophthalmol 2011;4:89.

41. Kreutzer TC, Wolf A, Dirisamer M, et al. Intravitreal ranibizumab versus isovolemic hemodilution in the treatment of macular edema secondary to central retinal vein occlusion: twelve-month results of a prospective, randomized, multicenter trial. Ophthalmologica 2015;233:8-17.

42. Ding X, Li J, Hu X, et al. Prospective study of intravitreal triamcinolone acetonide versus bevacizumab for macular edema secondary to central retinal vein occlusion. Retina 2011;31:838-45.

43. Gado AS, Macky TA. Dexamethasone intravitreous implant versus bevacizumab for central retinal vein occlusion-related macular oedema: a prospective randomized comparison. Clin Exp Ophthalmol 2014;42:650-5.

44. Haller JA, Bandello F, Belfort R, et al. Randomized, shamcontrolled trial of dexamethasone intravitreal implant in patients with macular edema due to retinal vein occlusion. Ophthalmology 2010;117:1134-46

45. Haller JA, Bandello F, Belfort R, et al. Dexamethasone intravitreal implant in patients with macular edema related to branch or central retinal vein occlusion twelve-month study results. Ophthalmology 2011;118:2453-60.

46. Yeh WS, Haller JA, Lanzetta P, et al. Effect of the duration of macular edema on clinical outcomes in retinal vein occlusion treated with dexamethasone intravitreal implant. Ophthalmology 2012;119:1190-8.

47. Aggermann T, Brunner S, Krebs I, et al. A prospective, randomised, multicenter trial for surgical treatment of central retinal vein occlusion: results of the Radial Optic Neurotomy for Central Vein Occlusion (ROVO) study group. Graefes Arch Clin Exp Ophthalmol 2013;251:1065-72.

48. Myers $\mathrm{D}$, Blodi $\mathrm{B}$, Ip M, et al. Reading center evaluation of OCT images from patients enrolled in the standard care vs. Corticosteroid for Retinal Vein Occlusion (SCORE) Study. Investigative Ophthalmology \& Visual Science 2006;47:5194.

49. Bhavsar AR, Ip MS, Glassman AR. The risk of endophthalmitis following intravitreal triamcinolone injection in the DRCRnet and SCORE clinical trials. Am J Ophthalmol 2007;144:454-6.

50. Oden NL, VanVeldhuisen PC, Scott IU, et al. Temporal variability of OCT in retinal vein occlusion participants in the SCORE study. Investigative Ophthalmology \& Visual Science 2007;48:107.

51. Ip M, Oden N, VanVeldhuisen P, et al. The standard care vs. corticosteroid for retinal vein occlusion study: design and baseline characteristics. Am Acad Ophthalmol 2008:260.

52. Scott IU, VanVeldhuisen PC, Oden NL, et al. SCORE Study report 1: baseline associations between central retinal thickness and visual acuity in patients with retinal vein occlusion. Ophthalmology 2009;116:504-12.

53. Scott IU, Blodi BA, Ip MS, et al. SCORE Study Report 2: Interobserver agreement between investigator and reading center classification of retinal vein occlusion type. Ophthalmology 2009;116:756-61.

54. Ip MS, Oden NL, Scott IU, et al. SCORE Study report 3: study design and baseline characteristics. Ophthalmology 2009;116:1770-7.

55. Domalpally A, Blodi BA, Scott IU, et al. The Standard Care vs Corticosteroid for Retinal Vein Occlusion (SCORE) study system for evaluation of optical coherence tomograms: SCORE study report 4. Arch Ophthalmol 2009;127:1461-7.

56. Ip MS, Scott IU, VanVeldhuisen PC, et al. A randomized trial comparing the efficacy and safety of intravitreal triamcinolone with observation to treat vision loss associated with macular edema secondary to central retinal vein occlusion: the Standard Care vs Corticosteroid for Retinal Vein Occlusion (SCORE) study report 5. Arch Ophthalmol 2009;127:1101.

57. Scott IU, Ip MS, VanVeldhuisen PC, et al. A randomized trial comparing the efficacy and safety of intravitreal triamcinolone with standard care to treat vision loss associated with macular Edema secondary to branch retinal vein occlusion: the Standard Care vs Corticosteroid for Retinal Vein Occlusion (SCORE) study report 6 . Arch Ophthalmol 2009;127:1115.

58. Scott IU, Oden NL, VanVeldhuisen PC, et al. SCORE Study Report 7 : incidence of intravitreal silicone oil droplets associated with stakedon vs luer cone syringe design. Am J Ophthalmol 2009;148:725-32.

59. Blodi BA, Domalpally A, Scott IU, et al. Standard Care vs Corticosteroid for Retinal Vein Occlusion (SCORE) Study system for evaluation of stereoscopic color fundus photographs and fluorescein angiograms: SCORE Study Report 9. Arch Ophthalmol 2010;128:1140-5.

60. Scott IU, VanVeldhuisen PC, Oden NL, et al. Baseline predictors of visual acuity and retinal thickness outcomes in patients with retinal vein occlusion: Standard Care Versus COrticosteroid for REtinal Vein Occlusion Study report 10. Ophthalmology 2011;118:345-52.

61. Chan CK, Ip MS, Vanveldhuisen PC, et al. SCORE Study report \#11: incidences of neovascular events in eyes with retinal vein occlusion. Ophthalmology 2011;118:1364-72.

62. Weinberg DV, Wahle AE, Ip MS, et al. Score Study Report 12: Development of venous collaterals in the Score Study. Retina 2013;33:287-95.

63. Domalpally A, Peng Q, Danis R, et al. Association of outer retinal layer morphology with visual acuity in patients with retinal vein occlusion: SCORE Study Report 13. Eye 2012;26:919-24.

64. Scott IU, Vanveldhuisen PC, Oden NL, et al. Baseline characteristics and response to treatment of participants with hemiretinal compared with branch retinal or central retinal vein occlusion in the standard care vs corticosteroid for retinal vein occlusion (SCORE) study: SCORE study report 14. Arch Ophthalmol 2012;130:1517-24.

65. Brown DM, Campochiaro PA, Singh RP, et al. Ranibizumab for macular edema following central retinal vein occlusion: six-month primary end point results of a phase III study. Ophthalmology 2010;117:1124-33.

66. Campochiaro PA, Brown DM, Awh CC, et al. Sustained benefits from ranibizumab for macular edema following central retinal vein occlusion: twelve-month outcomes of a phase III study. Ophthalmology 2011;118:2041-9.

67. Kinge B, Stordahl PB, Forsaa V, et al. Efficacy of ranibizumab in patients with macular edema secondary to central retinal vein occlusion: results from the sham-controlled ROCC study. Am J Ophthalmol 2010;150:310-4.

68. Boyer D, Heier J, Brown DM, et al. Vascular endothelial growth factor Trap-Eye for macular edema secondary to central retinal vein occlusion: six-month results of the phase 3 COPERNICUS study. Ophthalmology 2012;119:1024-32.

69. Brown DM, Heier JS, Clark WL, et al. Intravitreal aflibercept injection for macular edema secondary to central retinal vein occlusion: 1-year results from the phase 3 COPERNICUS study. Am J Ophthalmol 2013;155:429-37.

70. Gillies M. Intravitreal Vegf Trap-eye In Central Retinal Vein Occlusion: Results Of The Phase 3 Copernicus And Galileo Studies. Clinical \& Experimental Ophthalmology 2012;40:44.

71. Holz FG, Roider J, Ogura Y, et al. VEGF Trap-Eye for macular oedema secondary to central retinal vein occlusion: 6-month results of the phase III GALILEO study. Br J Ophthalmol 2013;97:278-84.

72. Epstein $D$, Algvere $P$, von Wendt $G$, et al. Long-term benefit from bevacizumab for macular edema in central retinal vein occlusion: 12 -month results of a prospective study. Acta Ophthalmologica 2012;90:48.

73. Epstein DL, Algvere PV, von Wendt G, et al. Bevacizumab for macular edema in central retinal vein occlusion: a prospective, randomized, double-masked clinical study. Ophthalmology 2012;119:1184-9.

74. Epstein DL, Algvere PV, von Wendt G, et al. Benefit from bevacizumab for macular edema in central retinal vein occlusion: twelve-month results of a prospective, randomized study. Ophthalmology 2012;119:2587-91.

75. Wells III JA. Pegabtanib sodium for treatment of macular edema secondary to Central Retinal Vein Occlusion (CRVO). Investigative Ophthalmology \& Visual Science 2006;47:4279.

76. Wells JA. Safety and efficacy of pegaptanib sodium in treating macular edema secondary to Central Retinal Vein Occlusion. Am Acad Ophthalmol 2006.

77. Ciulla TA. Treatment of macular edema following central retinal vein occlusion with pegaptanib sodium (macugen): a one-year study. Am Acad Ophthalmol 2007.

78. Pegaptanib CKG. Macugen) for Macular edema in Central Retinal Vein Occlusion: early OCT results and effect of therapy reinitiation. American Academy of Ophthamology 2007.

79. Wells III JA, Wroblewski JJ. Macugen in CRVO Study Group. Pegaptanib sodium for the treatment of macular edema following 
Central Retinal Vein Occlusion (CRVO): functional outcomes. Investigative Ophthalmology \& Visual Science 2007;48:1544.

80. Patel SS. Macugen in CRVO Study Group. Pegaptanib sodium for the treatment of macular edema following Central Retinal Vein Occlusion (CRVO): anatomical outcomes. Investigative Ophthalmology \& Visual Science 2007;48:311.

81. Ramezani A, Esfandiari $\mathrm{H}$, Entezari M, et al. Three intravitreal bevacizumab versus two intravitreal triamcinolone injections in recent onset central retinal vein occlusion. Acta Ophthalmol 2014;92:e530-9.

82. Hoerauf H, Feltgen N, Weiss C, et al. Clinical Efficacy and Safety of Ranibizumab Versus Dexamethasone for Central Retinal Vein Occlusion (COMRADE C): A European Label Study. Am J Ophthalmol 2016;169:258-67.

83. Miller JW, Le Couter J, Strauss EC, et al. Vascular endothelial growth factor a in intraocular vascular disease. Ophthalmology 2013;120:106-14.

84. Holden WL. Benefit-risk analysis. Drug Saf 2003;26:853-62.

85. Funk M, Kriechbaum K, Prager F, et al. Intraocular concentrations of growth factors and cytokines in retinal vein occlusion and the effect of therapy with bevacizumab. Invest Ophthalmol Vis Sci 2009;50:1025-32.

86. Papadopoulos N, Martin J, Ruan Q, et al. Binding and neutralization of vascular endothelial growth factor (VEGF) and related ligands by VEGF Trap, ranibizumab and bevacizumab. Angiogenesis 2012;15:171-85.

87. Yong M, Zhou M, Deng G. Photodynamic therapy versus antivascular endothelial growth factor agents for polypoidal choroidal vasculopathy: a meta-analysis. BMC Ophthalmol 2015;15:1.

88. Gu X, Yu X, Song S, et al. Intravitreal Dexamethasone Implant versus Intravitreal Ranibizumab for the Treatment of Macular Edema Secondary to Retinal Vein Occlusion in a Chinese Population. Ophthalmic Res 2017;58:8-14.

89. Hattenbach LO, Feltgen N, Bertelmann T, et al. Head-to-head comparison of ranibizumab PRN versus single-dose dexamethasone for branch retinal vein occlusion (COMRADE-B). Acta Ophthalmol 2018;96. 